\title{
RETRACTED ARTICLE: Multimorbidity: not just an older person's issue. Results from an Australian biomedical study
}

\author{
Anne W. Taylor $\cdot$ Kay Price $\cdot$ Tiffany K. Gill • \\ Robert Adams $\cdot$ Rhiannon Pilkington · \\ Natalie Carrangis $\cdot$ Zumin Shi $\cdot$ David Wilson
}

Received: 15 February 2010/Accepted: 18 October 2010/Published online: 13 November 2010

(C) The Author(s) 2011. This article is published with open access at Springerlink.com

The Publisher and the authors herewith retract this article, as it was due to a technical mishap erroneously published in Social Psychiatry and Psychiatric Epidemiology, whereas it was intended to be published in BMC Public Health. You can find the same article published in BMC Public Health here: http://dx.doi.org/10.1186/1471-2458-10-718.

A. W. Taylor $(\bowtie) \cdot$ T. K. Gill · R. Pilkington $\cdot$ Z. Shi

South Australian Department of Health,

Population Research and Outcome Studies,

PO Box 287, Rundle Mall, Adelaide, SA 5000, Australia

e-mail: Anne.taylor@adelaide.edu.au

T. K. Gill

e-mail: Tiffany.gill@health.sa.gov.au

R. Pilkington

e-mail: Rhiannon.pilkington@health.sa.gov.au

Z. Shi

e-mail: Zumin.shi@health.sa.gov.au

A. W. Taylor · T. K. Gill · Z. Shi

Department of Medicine, University of Adelaide,

Adelaide, Australia

K. Price

School of Nursing and Midwifery,

University of South Australia, Adelaide, Australia

e-mail: Kay.price@unisa.edu.au

R. Adams · D. Wilson

Health Observatory, Queen Elizabeth Hospital,

University of Adelaide, Adelaide, Australia

e-mail: Robert.adams@adelaide.edu.au

D. Wilson

e-mail: David.wilson@adelaide.edu.au

N. Carrangis

Health Promotion, South Australian Department of Health,

PO Box 287, Rundle Mall, Adelaide, SA 5000, Australia

e-mail: Natalie.carrangis@health.sa.gov.au 